Journal of Applied Mathematics and Stochastic Analysis

9, Number 3, 1996, 333.

SHORT REPORTS AND COMMUNICATIONS

\title{
GENERALIZED VARIATIONAL INEQUALITIES AND ASSOCIATED NONLINEAR EQUATIONS
}

\author{
Accepted for publication to the \\ Czechoslovak Mathematical Journal \\ RAM U. VERMA \\ International Publications \\ 12046 Coed Drive \\ Orlando, FL 32826 USA \\ and \\ Istituto per la Ricerca di Base \\ Division of Mathematics \\ I-86075 Monteroduni (IS), Molise, Italy
}

Let $H$ be a real Hilbert space and let $K$ be a nonempty closed convex subset of $H$. Let $\langle\cdot, \cdot\rangle$ and $\|\cdot\|$ denote the inner product and norm of $H$, respectively. For given operators $f, T: H \rightarrow H$ on $H$, we consider a class of generalized variational inequality (GVI) problems of determining an element $x$ in $H$ such that $f(x)$ is in $K$ and

$$
\langle f(x)-T(x), v-f(x)\rangle \geq 0 \text { for all } v \text { in } K,
$$

where $g$ is Lipschitzian strongly monotone and $T$ is Lipschitzian relaxed Lipschitz. The solvability of the GVI problem is based on an application of a modified iterative algorithm. 


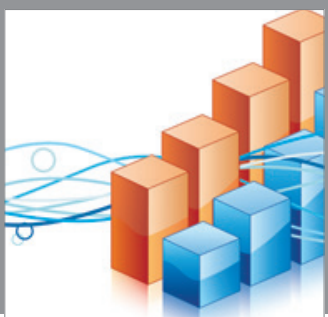

Advances in

Operations Research

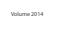

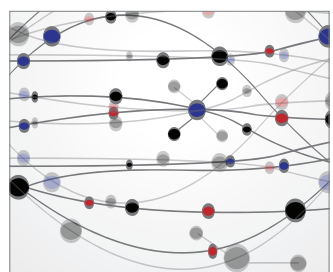

\section{The Scientific} World Journal
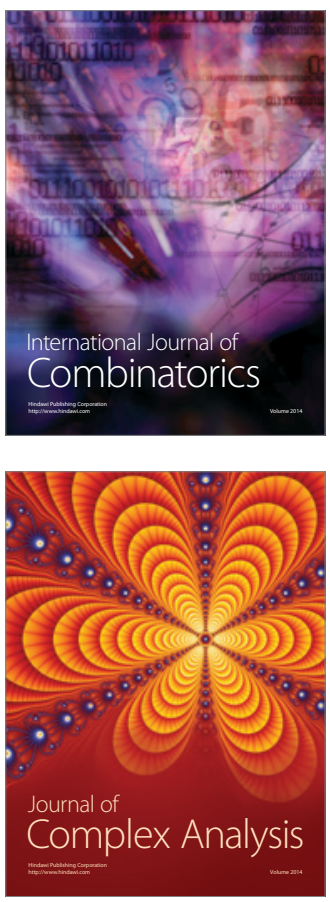

International Journal of

Mathematics and

Mathematical

Sciences
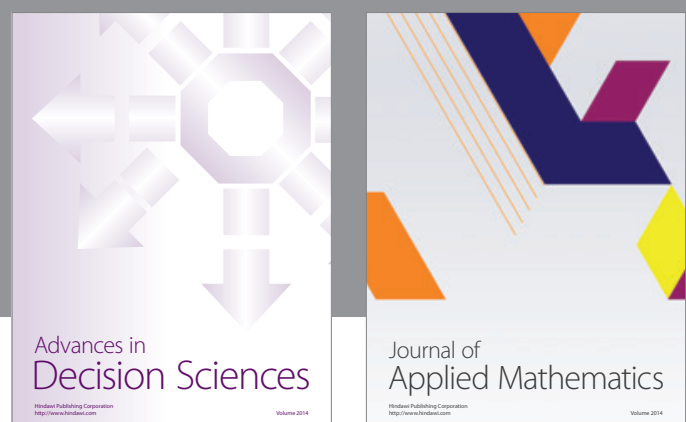

Journal of

Applied Mathematics
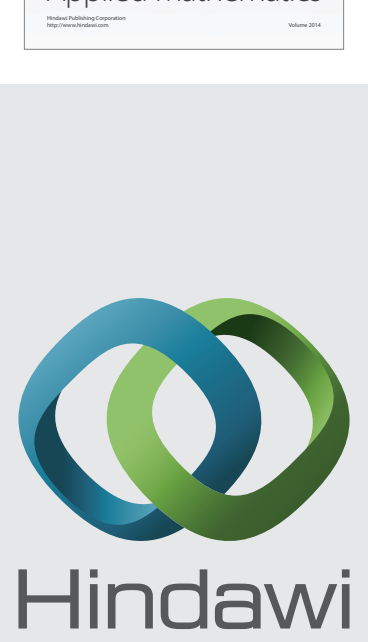

Submit your manuscripts at http://www.hindawi.com
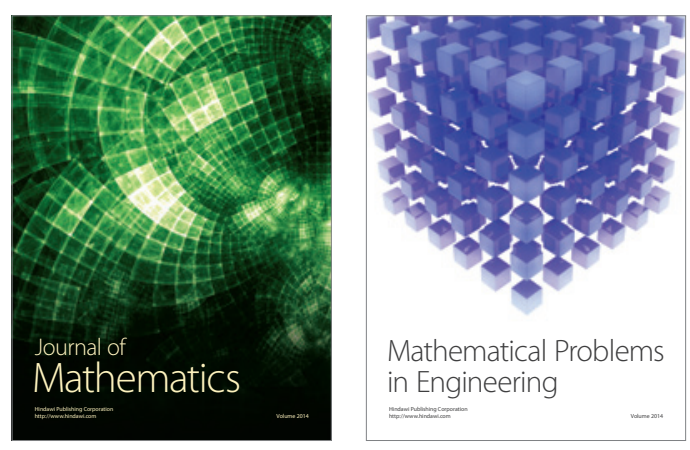

Mathematical Problems in Engineering
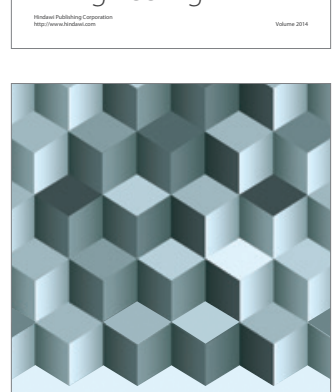

Journal of

Function Spaces
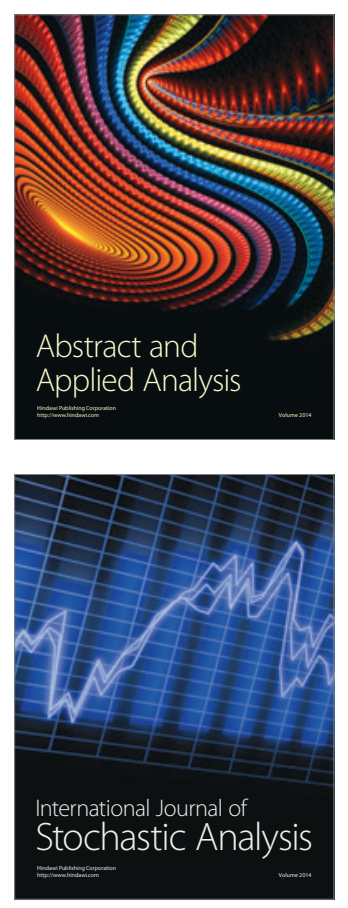

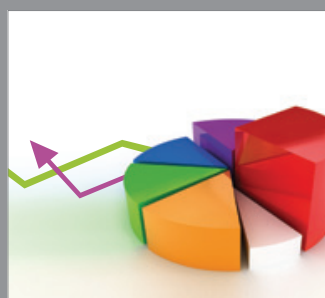

ournal of

Probability and Statistics

Promensencen
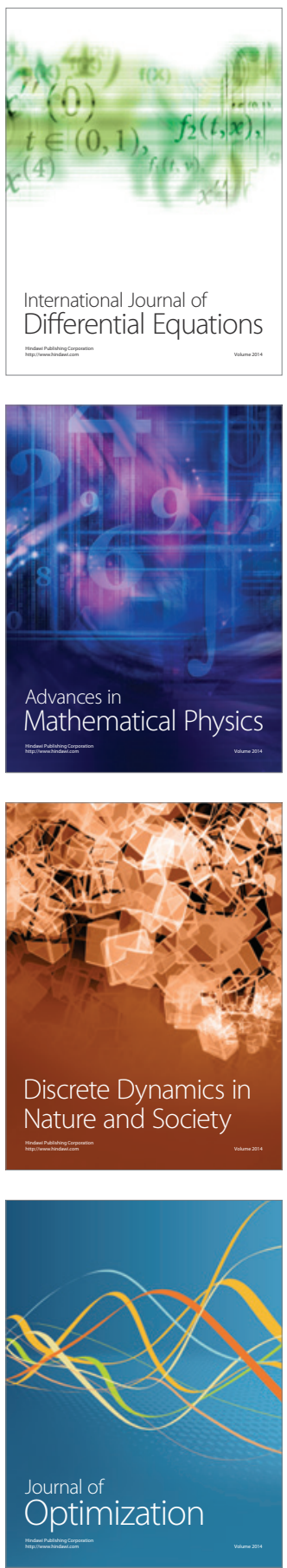